\title{
Jean Picq, Politique et religion. Relire l'histoire, éclairer le présent
}

Paris, Presses de Sciences Po, 2016, 221 p.

\section{Vincent Petit}

\section{(2) OpenEdition}

\section{Journals}

Édition électronique

URL : http://journals.openedition.org/assr/28320

DOI : $10.4000 /$ assr. 28320

ISSN : $1777-5825$

\section{Éditeur}

Éditions de l'EHESS

Édition imprimée

Date de publication : 31 décembre 2016

Pagination : 367

ISSN : 0335-5985

Référence électronique

Vincent Petit, « Jean Picq, Politique et religion. Relire l'histoire, éclairer le présent », Archives de sciences sociales des religions [En ligne], 176 | octobre-décembre 2016, mis en ligne le 20 juillet 2017, consulté le 24 septembre 2020. URL : http://journals.openedition.org/assr/28320 ; DOI : https://doi.org/10.4000/ assr.28320

Ce document a été généré automatiquement le 24 septembre 2020.

(c) Archives de sciences sociales des religions 


\title{
Jean Picq, Politique et religion. Relire l'histoire, éclairer le présent
}

Paris, Presses de Sciences Po, 2016, 221 p.

\author{
Vincent Petit
}

\section{RÉFÉRENCE}

Jean Picq, Politique et religion. Relire l'histoire, éclairer le présent, Paris, Presses de Sciences Po, 2016, $221 \mathrm{p}$.

1 Jean Picq, haut fonctionnaire, enseigne la philosophie politique et l'histoire de l'État à Sciences Po. Il a récemment publié La Liberté de religion dans la République. L'esprit de laïcité (Paris, Odile Jacob, 2014). Ce petit livre traite d'une problématique dans l'air du temps : comment assurer la coexistence pacifique des différents cultes au sein d'une société pluraliste? La réponse, un brin téléologique, court essentiellement sur le deuxième millénaire de l'histoire occidentale avec une sympathie à peine dissimulée pour le cas anglais. Cette relecture construite sur des historiens du droit anglo-saxons (Berman, Skinner) et des philosophes (Lévinas, Ricœur, Lefort) mobilise un matériau abondant qui peut servir de manuel utile de propédeutique. Évidemment un tel survol encourt le risque de présenter certaines simplifications qui contredisent l'ensemble de la démonstration. L'Édit de Nantes, comme le dit l'avertissement placé au début de volume, "annonçait lointainement la tolérance et le régime de laïcité qui seront consacrés par la loi de séparation des Églises et de l'État de 1905 »; or, comme l'écrit plus loin l'auteur, l'Édit met en place une «territorialisation» (p. 69, 90), autrement dit une «communautarisation » religieuse, qui s'inscrit dans la logique des privilèges de l'époque moderne, mais qui est totalement incompatible dans le cadre de l'État tel qu'on l'entend aujourd'hui, surtout en France. On regrettera cette phrase : « Reprenant, en le poussant à l'extrême, l'antijudaïsme chrétien, Hitler fait du racisme le fondement de son action» (p. 157). Ian Kershaw a montré que les régions catholiques, ou plus exactement les régions les plus encadrées par l'Église catholique, avaient été les plus 
rétives au nazisme. L'encyclique Mit brennender Sorge arrive peut-être "bien tard" (p. 160), mais toujours plus tôt que les réactions de certains États, organismes internationaux ou intellectuels. Enfin, le concile Vatican II est présenté comme un ralliement à l'autonomie politique de l'État et au pluralisme religieux: «L'Église ne prétend plus commander, elle invite à obéir à l'autorité légitime» (p.172). Sauf que l'Église a toujours invité à obéir à l'autorité légitime : faut-il le demander aux Polonais en révolte contre l'empire russe en 1832 ? Il ne s'agit pas ici de ruiner la démarche de l'auteur dont nous partageons l'essentiel des préoccupations, mais de pointer l'impensé de la philosophie politique qu'il défend. Tout acquise à l'État moderne, rationnel, pacificateur, elle transpire un préjugé défavorable à toute forme de corporation religieuse et n'envisage l'Église que sur le mode hobbesien d'une congrégation sous le contrôle de l'État et acquise aux valeurs sociales dominantes (libérale, démocratique, nationale, égalitaire, etc.), alors même qu'en creux elle souligne les avantages d'une religion hiérarchiquement organisée et autonome (pour conclure un concordat, acte «bilatéral », p. 147, il faut être deux). D'autre part, les problèmes soulevés dans les sociétés occidentales par l'islam peuvent-ils se résoudre en étudiant la généalogie occidentale de la sécularisation qui, par définition, ne l'a pas ou si peu affecté, et par laquelle il peut ne pas se sentir concerné ? Enfin, la loi de 1905 est présentée comme le texte fondateur du " régime de laïcité », sauf que, comme le répète Émile Poulat (Scruter la loi de 1905. La République française et la Religion, Paris, Fayard, 2010, non cité dans la bibliographie), elle ne sépare pas le politique et le religieux, le temporel et le spirituel, et se contente, si l'on peut dire, de mettre fin à l'organisation du culte par l'État et d'en garantir l'exercice public. 